\title{
Aby Warburg, Fragmente zur Ausdruckskunde
}

\section{Hélène Ivanoff}

\section{OpenEdition \\ Journals}

Édition électronique

URL : http://journals.openedition.org/ifha/8973

DOI : 10.4000/ifha. 8973

ISSN : 2198-8943

Éditeur

IFRA - Institut franco-allemand (sciences historiques et sociales)

\section{Référence électronique}

Hélène Ivanoff, « Aby Warburg, Fragmente zur Ausdruckskunde », Revue de l'IFHA [En ligne], Date de recension, mis en ligne le 13 décembre 2017, consulté le 24 septembre 2020. URL : http:// journals.openedition.org/ifha/8973 ; DOI : https://doi.org/10.4000/ifha.8973

Ce document a été généré automatiquement le 24 septembre 2020.

(C)IFHA 


\section{Aby Warburg, Fragmente zur Ausdruckskunde}

Hélène Ivanoff

\section{RÉFÉRENCE}

Ulrich Pfisterer, Hans Christian Hönes (dir.), Aby Warburg - Fragmente zur Ausdruckskunde, Aby Warburg - Gesammelte Schriften - Studienausgabe, vol. IV, Berlin: de Gruyter, 2015, 372 p., $59,95 €$ 
Le quatrième volume des œuvres complètes d'Aby Warburg documente ses premières tentatives pour poser les fondements théoriques de son concept d'image et de symbole et pour élaborer une "psychologie moniste de l'art» durant les années 1888-1905. Dans le sillage de la biographie intellectuelle publiée par Ernst Gombrich en 1970 (Aby Warburg. An Intellectual Biography), il participe ainsi à la redécouverte des écrits de l'historien de l'art et de la culture, complétant les volumes déjà parus concernant la Renaissance européenne (Die Erneuerung der heidnischen Antike), l'Atlas Mnémosyne (Der Bilderatlas Mnemosyne), ses conférences (Bilderreihen und Ausstellungen) et son journal (Tagebuch der Kulturwissenschaftlichen Bibliothek Warburg). Issu de la coopération entre l'Institut Warburg de Londres et le séminaire d'histoire de l'art de l'université de Hambourg, il contribue à une meilleure connaissance de la pensée du jeune Warburg, tout en poursuivant la publication systématique de ses archives grâce au soutien de la fondation Thyssen.

Le livre comprend quatre parties. La première, la plus conséquente, présente une philosophie psychologique de l'art à travers les notes de lectures prises par Aby Warburg de février 1888 à janvier 1903 et complétées entre 1905 et 1912. Les références à Darwin, Bastian, Vischer, Carlyle, Semper, Lasson, Dilthey, Lamprecht, Haeckel, Riegl et Justi, entre autres, appuient ses premières réflexions sur les notions de psychologie de l'art, d'ornement, de symbole et d'expression. La deuxième partie réunit les remarques que l'étudiant rédigea entre 1889 et 1891 à propos du livre d'Heinrich Wölfflin, Renaissance und Barock. Eine Untersuchung über Wesen und Entstehung des Barockstils in Italien, paru en 1888. La troisième rassemble les arguments avancés par Aby Warburg pour défendre sa thèse de doctorat en quatre versions entre 1892 et 1906, manuscrite, imprimée, retravaillée, la dernière correspondant à la version finale soutenue et corrigée. La quatrième partie est consacrée à un essai non publié entrepris lors de son voyage aux États-Unis et parachevé de façon sporadique jusqu'en 1901, Le Symbolisme comme facteur déterminant (Symbolismus als Umfangsbestimmung).

S'ils ne délivrent pas une pensée achevée et construite, ces fragments ont pour mérite de mettre en lumière les fondements d'une théorie générale de l'image et du symbole élaborée par Aby Warburg entre 1888 et 1905 : durant sa thèse portant sur Sandro Botticelli en 1892-1893, il donne une conférence sur Dürer où il développe son concept central de «formule du pathos » (Pathosformel) en 1905 et fait ses premières recherches en bibliothèque. Certes, ils déstabiliseront le lecteur habitué aux analyses totalisantes ou synthétiques d'Ernst Gombrich ou de Georges Didi-Huberman. Le croisement des différents textes et notes permet néanmoins de dégager des références, des étapes et des constantes dans l'élaboration de la pensée de l'historien d'art et met en exergue la 
cohérence et la logique de ses écrits depuis la rédaction de sa thèse. Il révèle son ambition de dresser un cadre théorique général et universel pour ses recherches empiriques, à l'opposé de l'inventaire d'images que fut pourtant l'Atlas Mnémosyne ou de l'étude de cas que représenta Le Rituel du serpent.

Le volume est donc une publication essentielle et charnière au sein des Euvres choisies qui donne accès aux archives des années de formation d'Aby Warburg, éclairant d'un nouveau jour l'entreprise intellectuelle de sa vie entière.

INDEX

Index chronologique : Époque contemporaine

Thèmes : Histoire de l'art

AUTEURS

HÉLÈNE IVANOFF

EHESS (CNRS-UMR 8131) 